Journal of Machine Engineering, 2020, Vol. 20, No. 3, 63-75

ISSN 1895-7595 (Print) ISSN 2391-8071 (Online)

Received: 19 January 2020 / Accepted: 15 April 2020 / Published online: 25 September 2020

temperature, measurement, deformation, displacement

\author{
Jessica DEUTSCH ${ }^{1}$, Tom ALBRECHT ${ }^{1 *}$ \\ Mirko RIEDEL ${ }^{2}$, Lars PENTER ${ }^{1}$ \\ Hajo WIEMER ${ }^{1}$, Jens MÜLLER ${ }^{1}$ \\ Steffen IHLENFELDT ${ }^{1,2}$
}

\title{
THERMO-ELASTIC STRUCTURAL ANALYSIS OF A MACHINE TOOL USING A MULTI-CHANNEL ABSOLUTE LASER INTERFEROMETER
}

\begin{abstract}
One of the main errors in the machining accuracy of machine tools is the displacement through thermal induced deformation. Modern design and construction methods aim to optimize the heat flow in the machine to achieve minimum displacement. To enable a further improvement it is essential to know the displacement state of the complete machine structure. However, most measurement methods that are used to capture the influence of a thermal load only measure the displacement of the TCP or individual axes. This paper presents a methodology to capture the complex spatial displacement condition of a state of the art machine tool in one measuring cycle using a multichannel laser interferometer. It describes the development of the measurement model as well as the measurement setup in the workspace of the machine. With measurements according to the presented procedure, it is possible to uncover weak points in the structure of a machine tool and to derive warm-up and cooling strategies.
\end{abstract}

\section{INTRODUCTION IN STRUCTURAL ANALYSIS}

In order to meet the increasing demands on productivity, it is often necessary to enhance the performance of machine tools. Either axis speed or, for example, cutting performance is increased in machining processes. This also raises the amount of power dissipation, which can lead to more pronounced thermally induced displacements in the machine [1].

The major part of research in this field focuses on calibration of machine tools to compensate or correct the thermally introduced error of motion axes or the tool centre point (TCP). The standard also only deals with these topics [2]. The main objective here is the volumetric correction of the measured deviation [3]. A number of laser-based measurement methods are recommended for measuring the geometric accuracy of machine tools [4]. Especially variations of the laser interferometer are often used to determine the geometric accuracy of machine tools or to provide data for the correction of volumetric errors [5].

\footnotetext{
${ }^{1}$ Institute of Mechatronic Engineering Dresden (IMD), TU Dresden, Germany

${ }^{2}$ Fraunhofer Institute for Machine Tools and Forming Technology (IWU), Dresden, Germany

*E-mail: tom_morris.albrecht@tu-dresden.de https://doi.org/10.36897/jme/127128
} 
The measurement of several points with a standard laser interferometer requires a manual intervention into the measuring arrangement. The duration of such a measurement may prevent the detection of transient influences on the structure. Tracking interferometers, also known as laser trackers or laser tracers, represent a further development. The laser beam follows a reflector which can be clamped into the tool holder. Much of the manual alignment is eliminated, allowing the measurement to be performed significantly faster at multiple positions. The device is set up at various positions in the workspace and the reflector is moved to predefined points. This measurement of the workspace in a spatial grid makes it possible to calculate the positioning error by multilateration [6]. So far, promising results have been achieved in the calibration of coordinate measuring machines and machine tools. This method offers a quick and easy way to characterize the behaviour of the TCP in the entire volume of the workspace [7].

Another way to deal with thermal errors in machine tools is a structural analysis to fully understand the character and influence of heat sources. This approach is more profound, because it focuses on identifying thermal weak points to qualitatively assess the contribution of individual structural components to the total deformation. The aim is not to eliminate the effect of thermal influence on the TCP. Suitable measuring methods need to be able to monitor any point of the machine structure. The procedure should be fast enough, to exclude possible transient thermal state changes during the measurement. In addition, it should be possible to measure at several points simultaneously in order to limit the test time. This could be realized by a complex measuring setup with dial gauges, which often restricts the machine's freedom of movement, especially when the measurement is carried out in the workspace [8].

Since the interferometer is only able to track one reflector, a structural analysis would still require repositioning of the reflector for more than one point of interest, which dramatically increases measuring time and effort. In contrast to a standard laser interferometer, a multichannel laser interferometer offers the possibility to monitor several self-selected points of a structure almost simultaneously. For the characterization of machine tools it is only necessary to attach mirrors to the machine structure and to align them with collimators. A measuring section is the length between a light-source (collimator) and a mirror, that reflects the light. Accuracy in the sub-micron range is possible over several meters. The metrological traceability is ensured by the reference to fundamental physical constants: In every measurement, the molecular absorption spectrum of a gas cell (that stays constant over decades) is scanned and the system is thus automatically recalibrated. The principle is described in detail in [9] and [10]. This traceability fulfils the requirement of superior accuracy for a distance measurement. The system is relatively new to the market. So far, it is being used in large scale metrology for monitoring of long time stability, deformation by temperature, work piece weight and foundation drift in many applications. In production environments, it is successfully used to monitor large scale work pieces and machine tools $[9,11]$. Although multichannel laser interferometer meets all requirements for a structural analysis, an application for it is not known.

This paper presents a measuring concept that uses a multichannel laser interferometer to monitor the resulting displacement of the structure of a machine tool and thus determine the origin of thermally induced displacements. Since the system is traceable, the measuring concept transfers the $1 \mathrm{D}$-distance measurement into a spatial 3D-displacement information 
by using a geometric model. The aim of this concept is a weak point analysis and not a calibration of the machine tool.

\section{CONCEPT AND IMPLEMENTATION OF THE MEASUREMENT SETUP}

The development of the measuring concept consists of three parts: first, the structure of the machine is analysed to decide what parts have to be tracked and where the largest deformation is expected. Second, the developed measurement concept is simulated and tested within a Monte-Carlo-Simulation. Third, the simulated results are validated with a real setup and measurements.

\subsection{ANALYSIS OF THE MACHINE'S STRUCTURE AND CONCEPT OF MEASUREMENT}

To illustrate the principle of the measuring concept, a two-spindle horizontal milling machine is used as an example. The machine consists of three important subsystems (see Fig. 1).
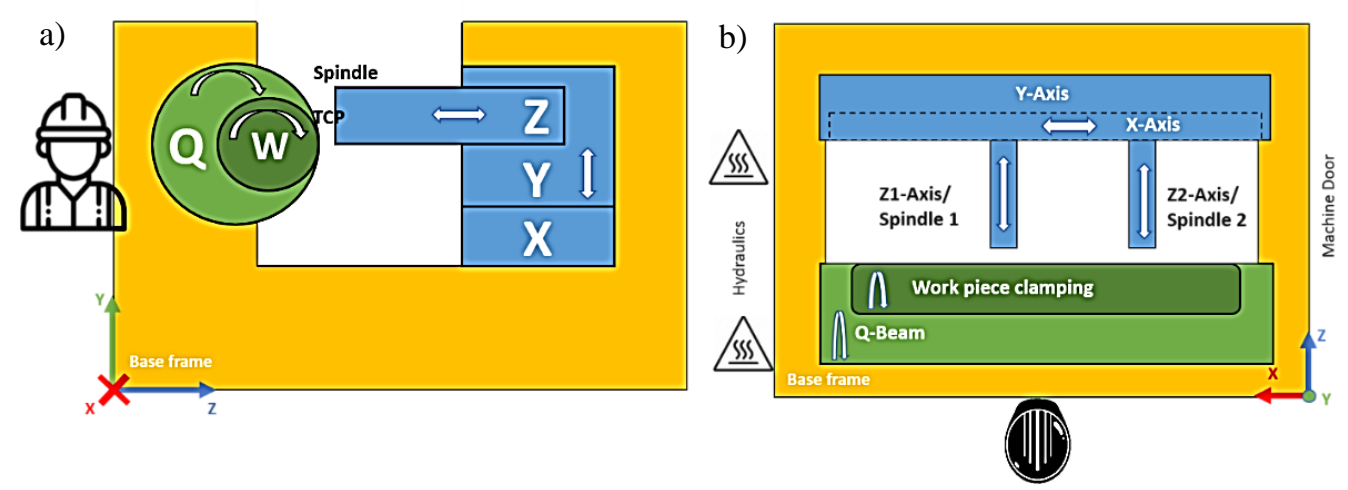

Fig. 1. Schematic configuration of machine: a) side view of machine tool, b) top view of machine tool

A three-axis unit holds two spindles (Z1- and Z2-Axis, blue) and carries out the machining process. The setup of this machine tool also includes a two-sided work piece changer "Q-beam", which is located opposite of the spindle (green). On one side, one work piece is machined while on the other side the next work piece can be prepared and clamped. The Qbeam can carry two work pieces at the same time. Both subsystems are located on the base frame of the machine (yellow). The interior of the machine, that has to be measured, is sized approximately $2 \mathrm{~m} \times 1 \mathrm{~m} \times 1 \mathrm{~m}$.

For the structural analysis of the machine behaviour under thermal load, the EtalonMultiline is available. This multichannel laser interferometer is able to measure absolute distances. According to the manufacturer, the system delivers an accuracy of $0.5 \mathrm{ppm}$ at a distance of up to $30 \mathrm{~m}$ [12].

The aim of the measurement is to determine the translatory degrees of freedom $(X-, Y-$, $Z$-direction) for each measuring point on the subsystems of the machine relative to each other. 
This allows to observe whether the thermal load has an influence on the base frame (represented by $B_{1}, B_{2}, B_{3}, B_{4}$ ) and what influence it has on the work piece clamping (consisting of $W_{1}, W_{2}$ and $Q_{1}, Q_{2}, Q_{3}, Q_{4}$ ). At those points the main deviation is expected (Fig. 2):
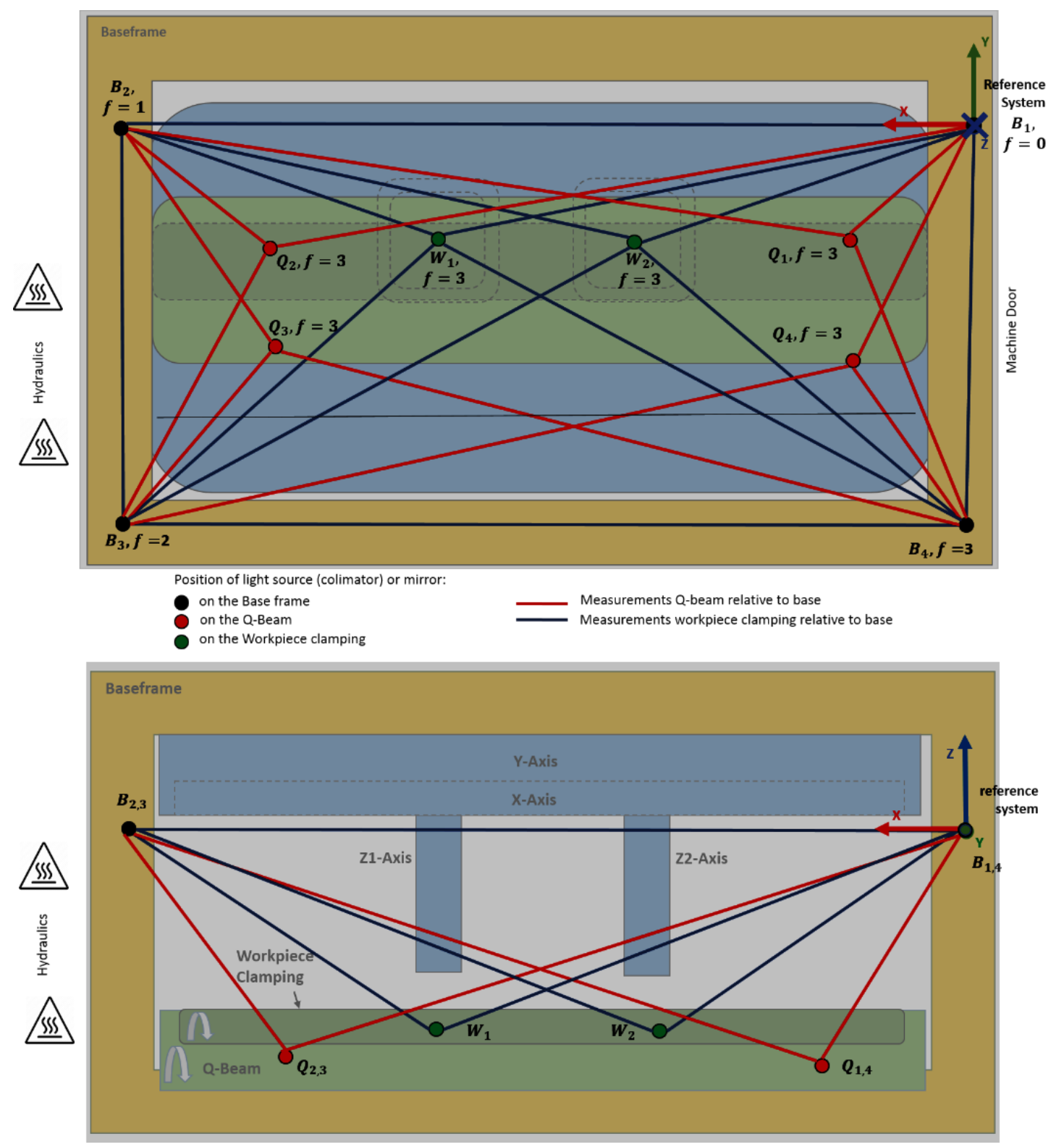

Fig. 2. Schematic Setup of machine structure and planned laser-beam network. Top: front-perspective, bottom: top-perspective

- $4 \times$ corner of Q-beam. $Q_{1}$ to $Q_{4}$ are positioned at the outermost corners of the solid body. - $2 \times$ clamping of the work pieces. $W_{1}$ and $W_{2}$ are representing the rotatory axis on the Qbeam and the contact zone from tool to work piece.

- $4 \times$ corner of base frame. $B_{1}$ to $B_{4}$ are positioned at the outermost corners of the solid base frame, at the level of the three-axis-unit. 
This analysis focuses on the displacement of Q-beam to work piece clamping, that cannot be measured with conventional measurement methods. This shows the advantage of the structural analysis compared to a plain TCP measurement.

This results in a system with 30 unknown coordinates, including 6 coordinates for the definition of a reference system, so we need a minimum of 24 measuring sections. The reference system is the origin of the measurement, where every measuring sections refers to. The definition of the system's origin with a 3-2-1 fixation is advisable. Also, the reference should be located on the machine part with least expected deformation. In consequence, the reference system lies on a plane on the base frame, consisting of the points $B_{1}, B_{2}, B_{3}$. Here, $B_{1}$ is defined constant in all three degrees of freedom, $B_{2}$ defines the $Y$-direction and $B_{3}$ is fixed in $Z$-direction, as shown in Fig. 2. Four measuring sections are connecting the measuring points $B_{1}, B_{2}, B_{3}$, and $B_{4}$ in the plane on the base frame.

For the spatial laser-beam network, measuring sections are implemented from base frame to work piece clamping. The measuring points $W_{1}$ and $W_{2}$ are having four measuring sections each. In addition, measuring sections are implemented from Q-beam to base frame. But the interior of the machine tool is narrow and the spindle heads protrude into the workspace. As a result, the measuring points $Q_{1}, Q_{2}, Q_{3}$ and $Q_{4}$ have three measuring sections each.

This results in a laser-beam network of 24 measuring sections for 24 unknown coordinates. It is desirable to know in advance if this network leads to a stable, computable model. We can estimate this simulatively (Goal 0). Next, we want to find out with which boundary conditions for the reference system the system of equation can be solved (Goal 1) and if the set-up is still good enough to obtain the desired accuracy (Goal 2).

\subsection{SIMULATION OF THE MEASUREMENT SETUP}

With these three goals in mind, the Monte-Carlo-simulation is a good way to achieve them. This method allows to test the planned network with different boundary conditions, to know in advance if the model can be solved (Goal 0 and 1). Furthermore, it provides a statistical analysis to estimate the model's accuracy (Goal 2). For this purpose, the input data is prepared as follows.

The laser-beam network consists of 10 measuring points along the machine parts. This results in a system with 30 unknown coordinates, including 6 coordinates for the definition of an origin of the reference system. So 24 measuring sections are available to determine 24 unknown coordinates. The coordinates are calculated from the measuring sections. For the calculation, the adjustment technique is used, with

$$
\boldsymbol{l}=\boldsymbol{A} * \boldsymbol{x}
$$

Where: $\boldsymbol{l}$ is a vector with all distance measurements, $\boldsymbol{A}$ is the Jacobian matrix (geometric model with representation of the arrangement of collimator and mirror in space) and $\boldsymbol{x}$ is the vector of unknown parameters, which is here the coordinates of the measuring points.

The geometrical model defines which collimator and which mirror link a common measuring section. With the given initial coordinates of all positions $P$ the geometric model 
calculates the resulting distances (Table 1). Also, the geometrical model defines the boundary conditions for the adjustment calculations. So within the model it can be decided for each individual unknown parameter whether or not it will be included in the adjustment (adjustment parameter $A x, A y, A z$ in Table 1. " 0 " means not included/fixed parameter, " 1 " means included/free parameter).

The geometrical model with differently configured boundary conditions is inserted in the Monte-Carlo-Simulation to find an optimum. With this method, systematic errors can be introduced in a targeted and separated manner. Table 1 shows the best configuration found, where the $Z$-coordinate of three basis-points is fixed, the $Y$-coordinates of two basis-points are fixed and the $X$-coordinate of one basis-point is fixed. This optimum corresponds to the proposed definition of the reference system in the laser-beam network (Goal 1). Those six parameters are not included in the adjustment and the equation system calculates with 24 unknowns, what makes it a determined system of equations.

Table 1. Configuration of geometric model and definition of boundary conditions for reference (adjustment parameters $A x, A y, A z .0$ means not included/fixed reference parameter, 1 means included/free parameter)

\begin{tabular}{|l|c|c|c|c|c|c|c|}
\hline $\begin{array}{l}\text { Location } \\
\text { in machine }\end{array}$ & $\begin{array}{l}\text { Name } \\
\text { of point }\end{array}$ & \multicolumn{3}{|c|}{ Coordinates of position P } & \multicolumn{3}{c|}{ Included in adjustment method? } \\
\hline & & $X$ & $Y$ & $Z$ & $A x$ & $A y$ & $A z$ \\
\hline Base & $B_{1}$ & 1000 & 300 & 0 & $0 /$ Ref & $0 /$ Ref & $0 /$ Ref \\
\hline Base & $B_{2}$ & -1000 & 300 & 100 & 1 & $0 /$ Ref & $0 /$ Ref \\
\hline Base & $B_{3}$ & -1000 & -300 & 100 & 1 & 1 & $0 /$ Ref \\
\hline Base & $B_{4}$ & 1000 & -300 & 0 & 1 & 1 & 1 \\
\hline Clamping & $W_{1}$ & 200 & 200 & 600 & 1 & 1 & 1 \\
\hline Clamping & $W_{2}$ & -200 & 200 & 600 & 1 & 1 & 1 \\
\hline Q-beam & $Q_{1}$ & 500 & 300 & 800 & 1 & 1 & 1 \\
\hline Q-beam & $Q_{2}$ & -500 & 300 & 800 & 1 & 1 & 1 \\
\hline Q-beam & $Q_{3}$ & -500 & -300 & 800 & 1 & 1 & 1 \\
\hline Q-beam & $Q_{4}$ & 500 & -300 & 800 & 1 & & 1 \\
\hline
\end{tabular}

For Monte-Carlo-Simulation, the geometric model with error-free position parameters for every collimator and mirror is defined. The (ideal) distance between two points is the output data of the geometric model. Now the task is to determine the inverse geometric model because in real measurement with the multichannel laser interferometer only distances are given, and the exact position P' must be calculated.

So the ideal distances of the geometric model are the new input data for the inverse geometric model and the positions of the collimators are the output parameters. To simulate a real measurement the distances are randomized with a normal distribution and a standard deviation of the given uncertainty of the multichannel-interferometer $(0.5 \mathrm{ppm})$ in the data sheet. The procedure can be seen in Fig. 3. As distance and pose have a functional relationship to each other, the inverse geometrical model and the mathematical adjustment model can describe the unknown coordinates $\mathrm{P}^{\prime}$ of the measuring points [13]. This is done 1000 times. 


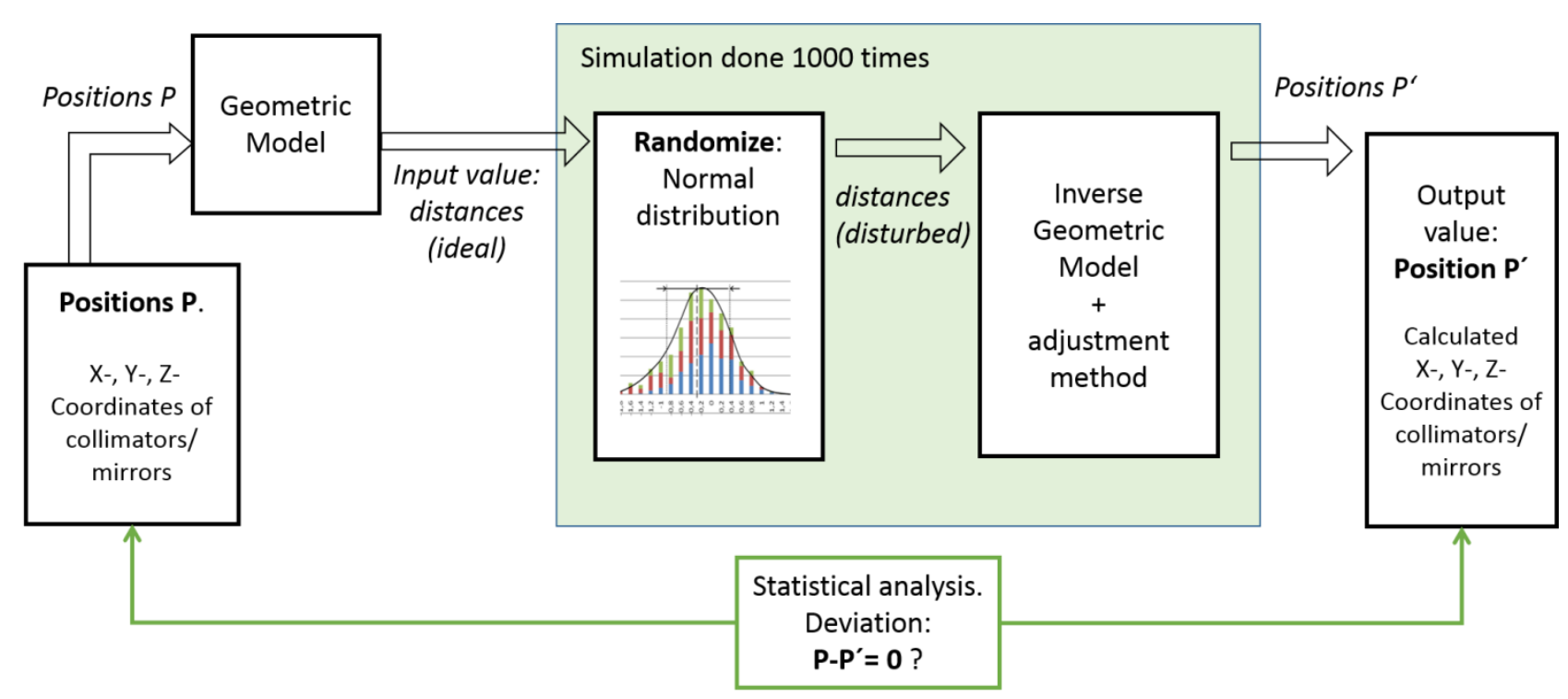

Fig. 3. Procedure of Monte-Carlo Simulation

The results of 1000 calculations form the basis for the statistical analysis. The output values $\mathrm{P}^{\prime}$ are compared to the ideal positions $\mathrm{P}$. The smaller the deviation of P-P' is, the better the agreement of the model with reality.

The results are shown in Table 2 . The small mean values of derivations $\Delta X, \Delta Y$ and $\Delta Z$ for six fixed parameters show, that the given geometrical model provides precise results. The small standard deviations ensure a good conformity of the simulation and the measuring network (Goal 2). The measuring concept was capable of determining all positions of measuring points along the machine structure.

Table 2. Statistical analysis for Monte-Carlo-Simulation done 1000 times

\begin{tabular}{|l|c|c|c|c|c|c|c|c|c|}
\hline \multirow{2}{*}{ P-P' $[\mathrm{mm}]$} & \multicolumn{3}{|c|}{$\begin{array}{c}\text { Measuring points on } \\
\text { base frame } B\end{array}$} & \multicolumn{3}{c|}{$\begin{array}{c}\text { Measuring points on work } \\
\text { piece clamping } W\end{array}$} & \multicolumn{4}{c|}{$\begin{array}{c}\text { Measuring points on } \\
\text { Q-beam }\end{array}$} \\
\hline & $\Delta x$ & $\Delta y$ & $\Delta z$ & $\Delta x$ & $\Delta y$ & $\Delta z$ & $\Delta x$ & $\Delta y$ & $\Delta z$ \\
\hline Mean value & 0.0003 & 0.0000 & 0.0014 & 0.0000 & 0.0008 & 0.0002 & 0.0001 & 0.0008 & 0.0004 \\
\hline $\begin{array}{l}\text { Standard } \\
\text { deviation: }\end{array}$ & 0.0109 & 0.0002 & 0.0435 & 0.0003 & 0.0211 & 0.0038 & 0.0024 & 0.0333 & 0.0175 \\
\hline Range: & 0.0959 & 0.0019 & 0.2356 & 0.0019 & 0.1649 & 0.0300 & 0.0229 & 0.2432 & 0.1941 \\
\hline
\end{tabular}

\section{COMMISSIONING AND IMPLEMENTATION}

The implementation of the mirrors and collimators in the machine requires good preparation, as it is difficult to install the equipment in the narrow interior of the machine. Therefore, the mounting heads for collimators and mirrors are attached in advance on the base plate. Then, the base plate is fixed in the machine (see Fig. 4) and collimators are inserted into the mounting heads. The same is done with the mirrors on the Q-beam and on the spindle head. 


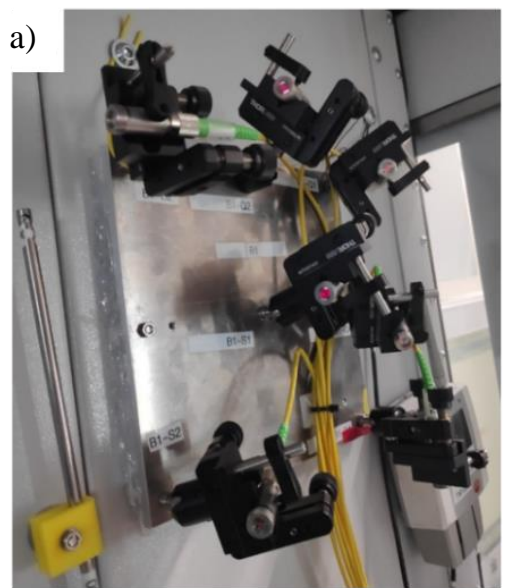

Measuring point $B 1$

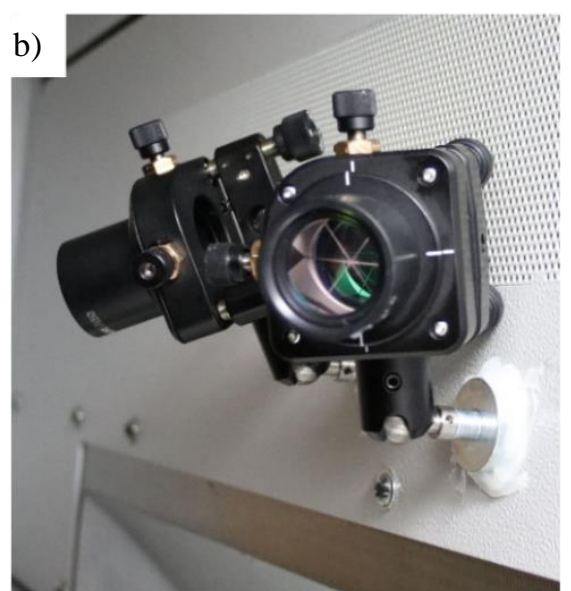

Measuring point $Q 1$

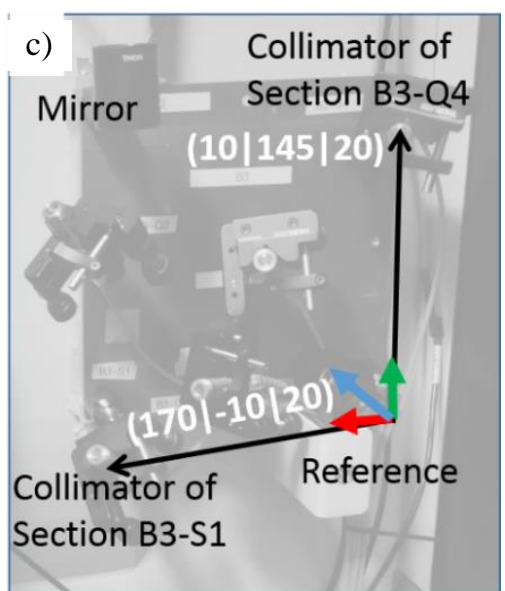

Measuring point $B 3$

Fig. 4. Measurement setup in the machine: a) base plate with collimators belonging to measurement point $B 1$ on the base frame on the door-side of the machine and an ambient temperature sensor, b) mirrors belonging to measurement point $Q 1$ on the Q- beam, c) baseplate with reference point for measuring sections of mirrors and collimators

In reality, not all the parts can be in the same place. Since all measuring sections per point need a common reference, the representation of the measuring points in the model is the bottom corner of the baseplate. For example there are five collimators located on the measuring point $B 3$ (see Fig. 4). Although both sections refer to the same measuring point $B 3$, the measuring section $B 3-Q 4$ has an offset to the measuring section $B 3-S 1$ (see Fig. 4). To be able to implement this in the model, the bottom corner of each base plate was measured and localized within the machine. It serves as common reference point for all parts mounted on it. The identified offsets are included in the geometric model (see Fig. 5).

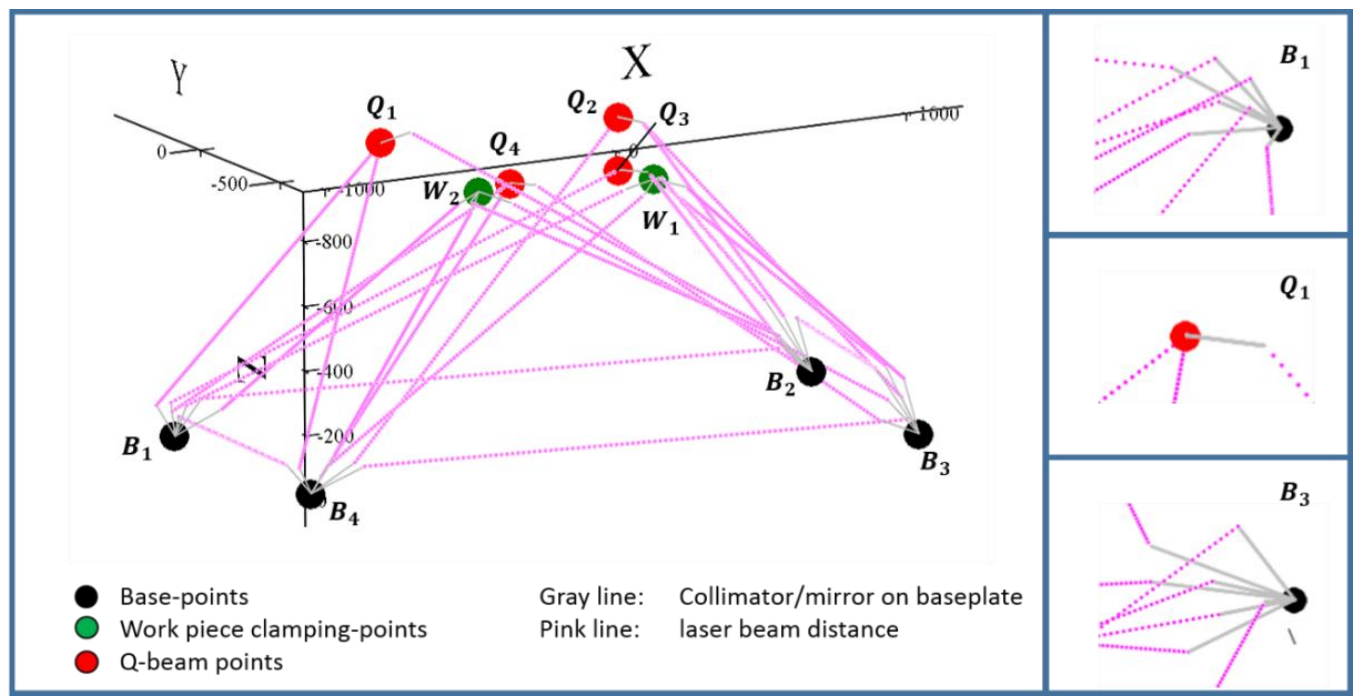

Fig. 5. Resulting laser-beam network of setup in machine and included offsets of points to base plate reference

An alignment laser can determine how reliable the distance measurement between the light source and the mirror works. Within the software of the multichannel laser interferometer, some parameters as light intensity can adjust the quality of the measurement. 
Moreover, several radio temperature sensors are installed in the interior of the machine, along the machine structure and on different heights on the wall of the room itself. On the one hand, this is done to obtain reliable information about the ambient temperature, on the other hand, optical measurements are highly dependent on the surrounding temperature and need correction values, if there are significant temperature changes over the measured sections. Now the measurement system set-up is available to analyse the machine.

In order to protect the machine from undesired external influences, the experiment was carried out in a climate cell. Within the cell, the ambient temperature and humidity can be controlled. Thus, the climate cell enables precise thermo-energetic analyses of machine tools. The ambient temperature load profile is shown in Table 3.

Table 3. Profiles of set ambient temperatures, representing usual temperature ranges in a shop floor

\begin{tabular}{|l|c|c|c|}
\cline { 2 - 4 } \multicolumn{1}{c|}{} & Profile "moderate" & Profile "warm" & Profile "cold" \\
\hline Max. Temperature & $25.0^{\circ} \mathrm{C}$ & $28.0^{\circ} \mathrm{C}$ & $22.0^{\circ} \mathrm{C}$ \\
\hline Min. Temperature & $18.0^{\circ} \mathrm{C}$ & $15.0^{\circ} \mathrm{C}$ & $15.0^{\circ} \mathrm{C}$ \\
\hline Range & $7.0 \mathrm{~K}$ & $13.0 \mathrm{~K}$ & $7.0 \mathrm{~K}$ \\
\hline
\end{tabular}

\section{RESULTS}

The presented results are calculated with six fixed parameters (see Section 2.2). The measurement is performed with the described temperature profile. Both spindles, $Z_{1}$ and $Z_{2}$, are moved with approx. $75 \%$ load when the measurement starts. In the following, the behaviour of the machine parts, represented by the measuring points is analysed to see if there is an influence of the temperature change on the structure.

It is apparent in the diagrams, that contrary to the previous simulation, the model also gives results with a small noise band. The reason for this is that the measurements were performed almost under ideal laboratory conditions. The climate cell allows an exact adjustment of humidity and temperature. The air volume in the working room is at rest during the measurement. The air pressure remains constant. The temperature change along the laserbeam is also monitored and adjusted by temperature sensors. These influences are part of the measurement uncertainty stated by the manufacturer. Due to the protected ambient conditions of the measurement, the achieved measurement uncertainty seems to be reduced.

Fig shows the deviation $\Delta X$ and $\Delta Y$ of $B 3$ and $B 4$ on the base frame due to the change of the ambient temperature according to the profiles in Table. It can be seen that the course of the graphs follows the set ambient temperature with a little delay. A clear thermally induced displacement of the base frame is detected. The maximum deviation of the measuring points on the wall-side in $x$-direction (B3) is $143.85 \mu \mathrm{m}$, and the maximum deviation of the door-sided measuring point $(B 4)$ is $71.53 \mu \mathrm{m}$. The temperature influence is significantly changing along the base frame structure. The reason is the configuration of the machine tool. Behind the wall-sided measuring points, the hydraulic unit is mounted and provides a high level of local heat input (compare Fig. 2). 


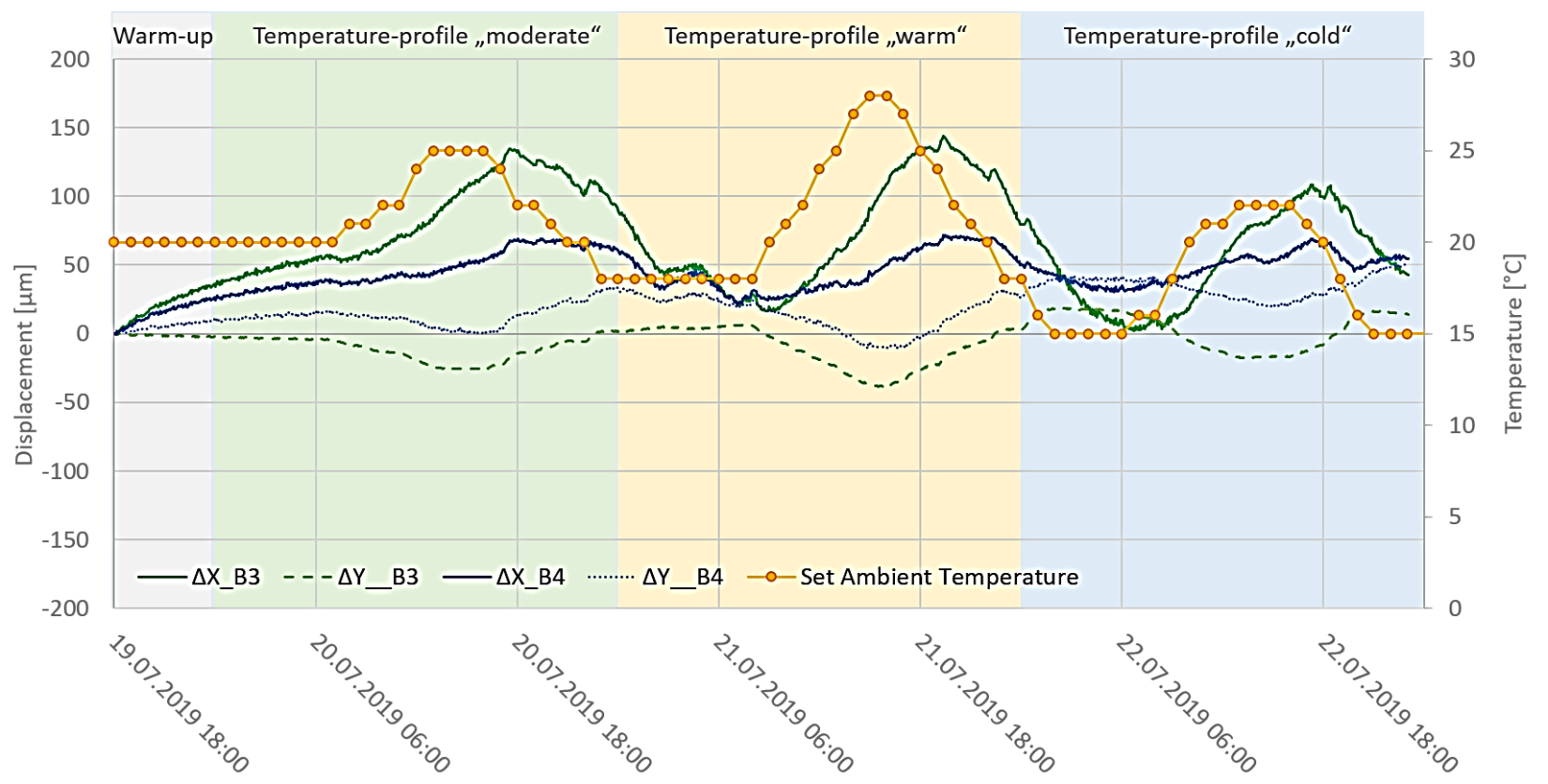

Fig. 6. Comparison of the displacement of $B 3$ and $B 4$ during changing ambient temperature conditions

The definition of the reference system (see Section 0.2) has impact for the interpretation. Since three of four basepoints are considered fixed in z-direction, we can detect the displacement of the work piece clamping and Q-beam relative to the base frame. Fig. 7 shows the displacement $\Delta X, \Delta Y$ and $\Delta Z$ of $Q 2$ and $Q 3$ according to the ambient temperature profiles. Both points are on the wall side. It becomes clear, that the Q-beam follows the changing ambient temperature.

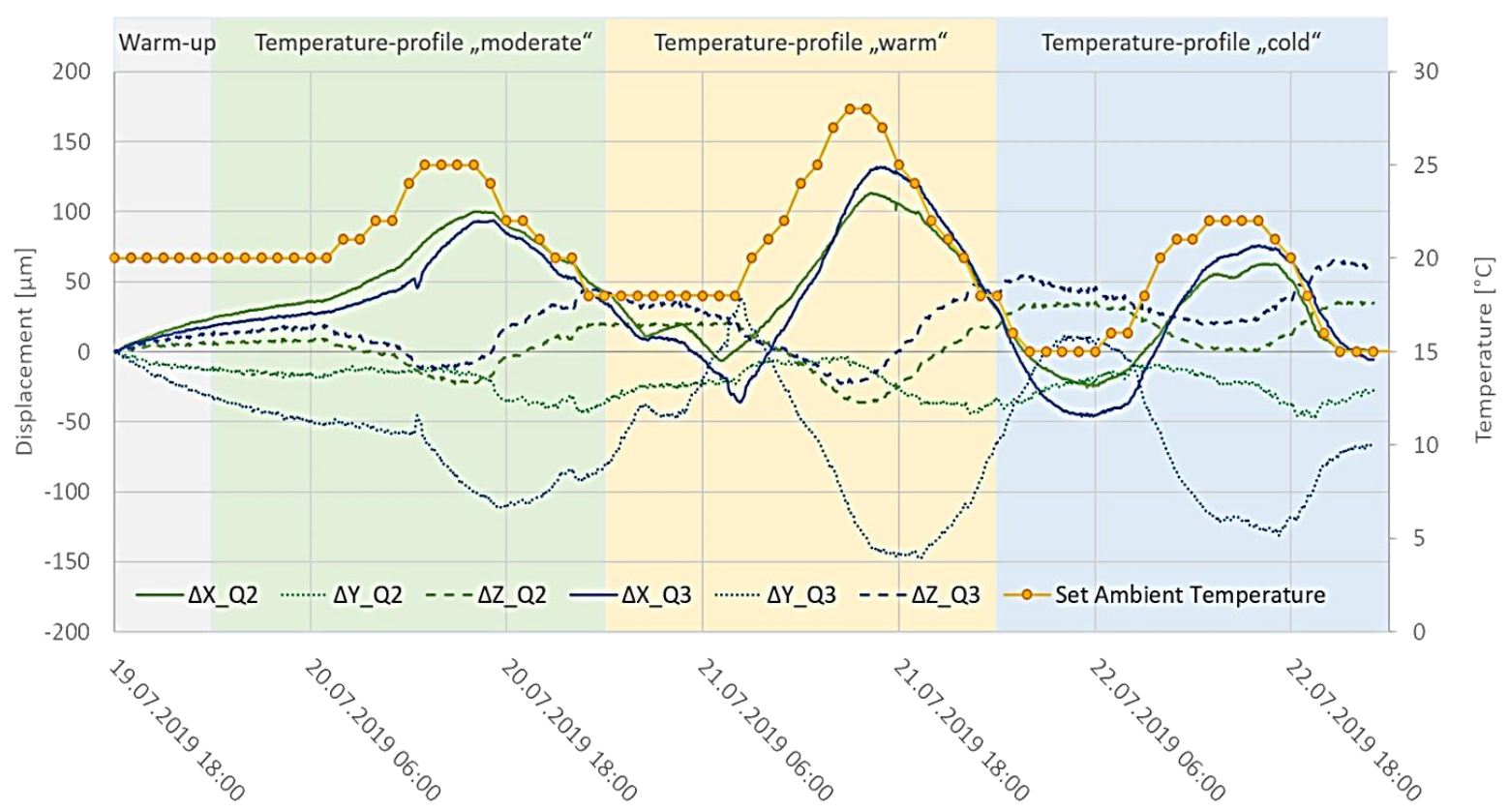

Fig. 7. Displacement of measuring points $Q 2$ and $Q 3$ on Q-beam (X-, Y-, Z-direction) during changing ambient temperature conditions 
The warmer the outside temperature, the higher the displacement in all three directions. The maximum deviation shows $Q 3$, with $131.86 \mu \mathrm{m}$ in $\mathrm{x}$-direction, $-147.48 \mu \mathrm{m}$ in $y$-direction and $65.92 \mu \mathrm{m}$ in $z$-direction. The diagram shows a similar course for the $x$ - and $z$-direction in both points. The deviation in $y$-direction of $Q 3$ is higher than that of $Q 2$. This indicates that the influence of the hydraulic unit is more significant on the bottom of the Q-beam. Concerning the coordinate system of the machine (see Fig. 2) this means a thermal expansion of the whole work piece changer $Q$, which is reasonable. However, at up to $0.15 \mathrm{~mm}$, the magnitude of the displacement is much higher than would be expected from a machine tool.

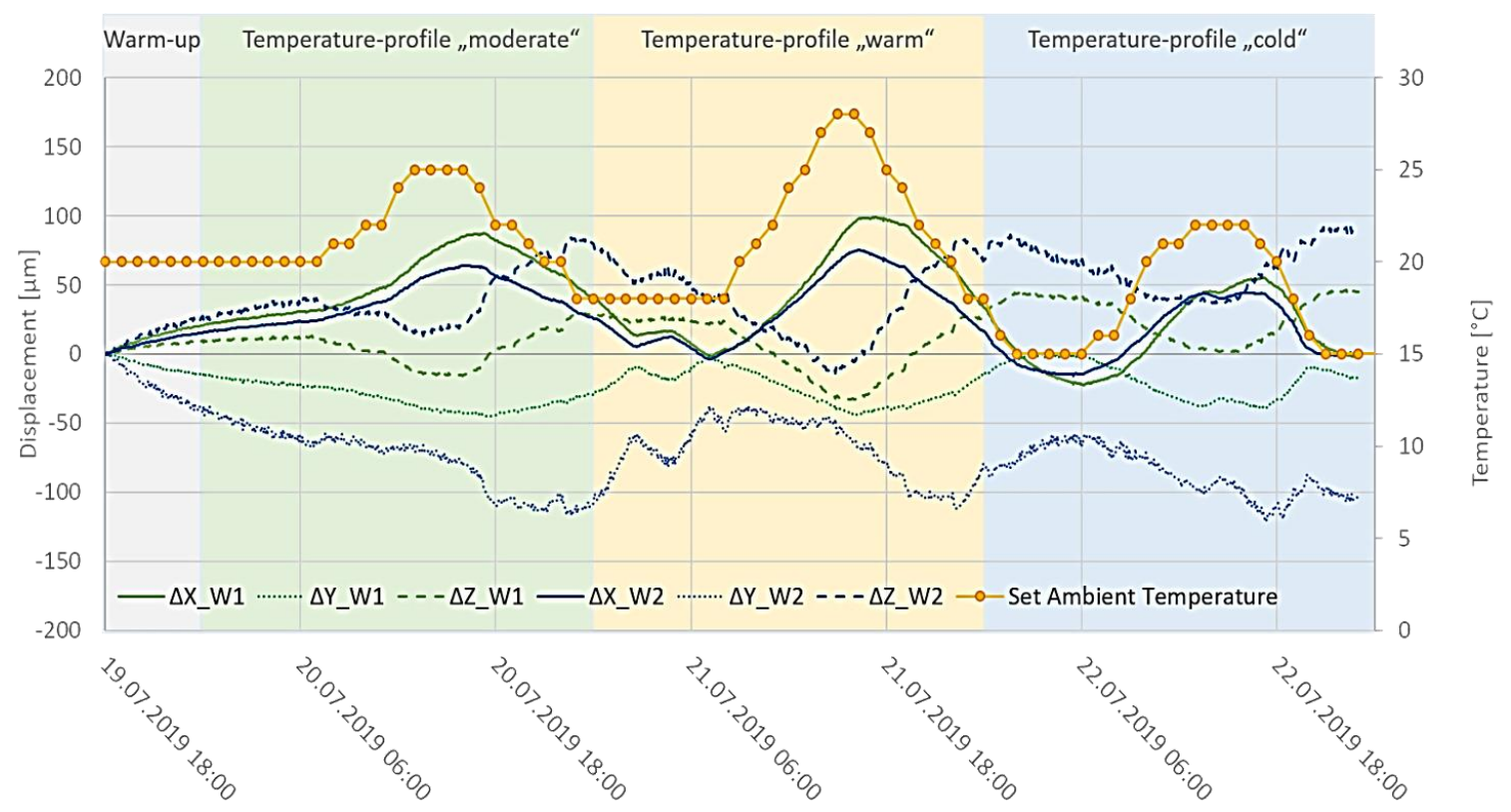

Fig. 8. Displacement of the work piece clamping $W 1$ and $W 2$

The displacement $\Delta X, \Delta Y$ and $\Delta Z$ of $W 1$ and $W 2$ is displayed in Fig. 8. The characteristic of the course over time is mostly similar to the diagrams shown before. It becomes obvious that the detected displacement of the Q-beam is transferred to the work piece clamping. The total deformation of the work piece clamping alone is considerably lower than for the Q-beam.

\section{CONCLUSION}

Thermal acquisition of a machine tool is time-consuming, cost-intensive and not state of the art. The question to be answered is: Which heat sources affect the accuracy of the machine to what extent and how can it be measured? In this paper, we showed the development of a measurement strategy that allows the detection of displacement of individual machine components with a multi-channel laser interferometer. In addition, it allows the characterization of thermally induced displacements, distortions and deformations in the machine tool. 
The development of the measurement concept took place in three steps. First, the structure of the machine was analysed to estimate where the largest deformation is expected and decide how to build up the laser beam network. Second, the developed measurement concept was simulated and tested with a Monte-Carlo-Simulation. The MonteCarlo method was used to investigate the individual influences of boundary conditions on the overall system. As the setup conditions where not ideal, it was important to compute, if the given geometric model is capable to calculate the unknowns and if it obtains the desired accuracy. Third, the simulated results are validated with a real setup and measurements.

Based on these results, weak points in the design can be identified and measures can be taken to eliminate them. For the analysed machine tool an insulating layer or a decoupling from the hydraulic system is one way to decrease the influence of the hydraulic system on the Q-beam and thus on the work piece clamping.

In general, the presented method is able to do a structural analysis. The strength of the measurement method is the detection of deformations of individual machine parts relative to each other, which remain undetected with a pure TCP measurement. Furthermore, with this method it is possible to detect locally induced thermal expansion and uncover weak points. With the results, temperature control strategies or constructive measures can be derived and verified. This helps machine tool manufacturers to increase thermal stability.

\section{ACKNOWLEDGEMENTS}

This research was funded by the German Research Foundation - Project-ID 174223256- TRR 96, which is gratefully acknowledged.

\section{REFERENCES}

[1] MAYR J., JEDRZEJEWSKI J., UHLMANN E., DONMEZ M.A., KNAPP W., HÄRTIG F., WENDT K., MORIWAKI T., SHORE P., SCHMITT R., BRECHER Ch., WÜRZ T., WEGENER K., 2012, Thermal Issues in Machine Tools, CIRP Annals - Manufacturing Technology, 61/2, 771-791.

[2] ISO 230-3, 2007, Test Code for Machine Tools - Part3: Determination of Thermal Effects.

[3] SCHWENKE H., KNAPP W., HAITJEMA H., WECKMANN A., 2008, Geometric Error Measurement and Compensation of Machines - An Update, CIRP Annals, 57/2, 660-675.

[4] DIN ISO 230-1, 1999, Prüfregeln für Werkzeugmaschinen, Teil 1: Geometrische Genauigkeit von Maschinen, die ohne Last oder unter Schlichtbedingungen arbeiten.

[5] IBARAKI S., KNAPP W., 2012, Indirect Measurement of Volumetric Accuracy for Three-Axis and Five-Axis Machine Tools: A Review, International Journal of Automation Technology, 6/2, 110-124.

[6] SCHWENKE H., FRANKE M., HANNAFORD J., KUNZMANN H., 2005, Error Mapping of CMMs and Machine Tools by a Single Tracking Interferometer, CIRP Annals, 54/1, 475-478.

[7] SCHWENKE H., SCHMITT R., JATZKOWSKI P., WARMANN C., 2009, On-the-Fly Calibration of Linear and Rotary Axes of Machine Tools and CMMs Using a Tracking Interferometer, CIRP Annals, 58/1, 477-480.

[8] WECK M., BRECHER C., 2006.,Werkzeugmaschinen Band 5 Messtechnische Untersuchung und Beurteilung, dynamische Stabilität, Springer Verlag.

[9] CABRAL A., ABREAU M., REBORDAO J.M., 2009, Absolute Distance Metrology for Long Distances with Dual Frequency Sweeping Interferometry, XIX IMEKO World Congress Fundamental and Applied Metrology.

[10] DALE J., HUGHES B., LANCASTER A.J., LEWIS A.J., REICHOLD A.J.H., WARDEN M.S., 2014, MultiChannel Absolute Distance Measurement System with Sub PPM-Accuracy and $20 \mathrm{~m}$ Range Using Frequency Scanning Interferometry and Gas Absorption Cells, Optics Express, 22/20, 24869-24893. 
[11] MUtilbA U., GOMEZ-ACEDO E., KORTABERRIA G., OLARRA A., YAGÜE-FABRA J.A., 2017, Tracability of On-Machine Tool Measurement: A Review, Sensors, 17/7, 1605.

[12] Absolute multiline technology, https://www.etalon-gmbh.com/produkte/absolute-multiline-technologie (Accessed: 2020-01-09).

[13] LUHMANN T., 2018, Nahbereichsphotogrammetrie: Grundlagen - Methoden - Beispiele, Wichmann Herbert, ISBN-10: 3879076405. 